\title{
Estimation of serum creatinine, serum urea, glomerular filtration rate and proteinuria among apparently healthy adults to assess the renal impairment and its association with body mass index: An observational hospital-based study
}

\author{
Singh Ray A. ${ }^{1}$, Kumar Kare P. ${ }^{2 *}$, Makwane H. ${ }^{3}$, Saxena T. ${ }^{4}$, Garg C. ${ }^{5}$ \\ DOI: https://doi.org/10.17511/ijmrr.2020.i02.09
}

\footnotetext{
${ }^{1}$ Amit Singh Ray, Associate Professor, Department of Medical Biochemistry, Gandhi Medical College, Bhopal, Madhya Pradesh, India.

2* Pawan Kumar Kare, Demonstrator, Department of Medical Biochemistry, Gandhi Medical College, Bhopal, Madhya Pradesh, India.

3 Haresingh Makwane, Assistant Professor, Department of Medical Biochemistry, Gandhi Medical College, Bhopal, Madhya Pradesh, India.

4 Tripti Saxena, Professor, Department of Medical Biochemistry, Gandhi Medical College, Bhopal, Madhya Pradesh, India.

${ }^{5}$ Chitransh Garg, MBBS Student, Department of Medical Biochemistry, Gandhi Medical College, Bhopal, Madhya Pradesh, India.
}

\begin{abstract}
Background: Serum urea, creatinine, and estimated glomerular filtration rate (eGFR) are the most widely accepted parameters for the assessment of renal impairment. Renal dysfunction in Indian obese adults has not been sufficiently investigated. Aims: To evaluate the renal function by using serum urea, serum creatinine, eGFR, and proteinuria in normal, overweight, and obese adults to identify renal impairment. Materials and Methods: This observational and cross-sectional study was done on a total of 100 normoglycemic, normotensive healthy adults, and these were divided into three groups as per the criteria of body mass index (BMI) as; normal, overweight and obese groups. Estimation of urea and creatinine was done by fully automated chemistry analyzer methods. Results: The present study was conducted in 100 normal study subjects which included 48 males and 52 females. A maximum number of subjects were found in the obese subgroup (34\%). Among subjects low eGFR prevalence was found $3 \%$ and prevalence of chronic kidney disease (CKD) was also found $3 \%$. Conclusions: A total of $3 \%$ prevalence of renal dysfunction was noted among adults and out of this $2 \%$ was found in obese adults. Therefore, it can be concluded that increasing BMI has a significant contributing factor for renal impairment in obese adults.
\end{abstract}

Keywords: Renal function, Proteinuria, Obesity, Chronic kidney disease

Corresponding Author

Pawan Kumar Kare, Demonstrator, Department of Medical Biochemistry, Gandhi Medical College, Bhopal, Madhya Pradesh, India. Email: pawankare4@gmail.com
How to Cite this Article

Ray AS, Kare PK, Makwane HS, Saxena T, Garg C. Estimation of serum creatinine, serum urea, glomerular filtration rate and proteinuria among apparently healthy adults to assess the renal impairment and its association with body mass index: An observational hospital-based study. Int J Med Res Rev. 2020;8(2):183-188.

Available From

https://ijmrr.medresearch.in/index.php/ijmrr/article/ view/1175
To Browse

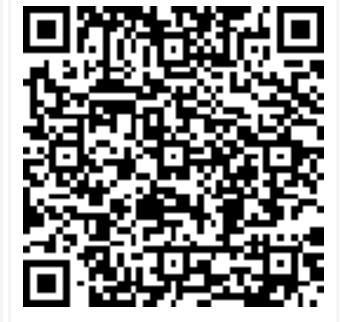




\section{Introduction}

Obesity is a major growing health concern in India due to its increasing prevalence found in younger and adult populations [1]. The most common causes for obesity are excessive food intake, lack of physical activities and genetic susceptibility [2] which makes this population more vulnerable to the adverse effects of obesity like; diabetes mellitus (DM), hypertension (HTN), ischemic heart disease (IHD) and chronic kidney disease (CKD) [3]. Among the adverse effects of obesity, renal problems have recently begun to attract more attention. Obesity is associated with alterations in adipose tissue that prompt to metabolic abnormalities [4].

A number of bioactive substances produced by adipose tissue such as adipokines, pro-inflammatory mediators, components of the renin-angiotensinaldosterone system (RAAS), and leptin induce proliferation of endothelial cells, hypertrophy of mesangial cells, vascular inflammation, oxidative stress and leads to renal fibrosis. Animal studies also show that the infusion of leptin into normal rats results in the development of glomerulosclerosis and proteinuria [5]. Therefore, with an increased prevalence of obesity, a significantly increased prevalence of renal diseases has been observed in various studies $[6,7]$.

Glomerular filtration rate (GFR), serum creatinine, serum urea, and excretion of albumin in urine are the well-known parameters for the assessment of renal function. Among these, GFR is one of the most important parameters used to determine the renal function and can be calculated with a different formula such as the modification of diet in renal disease study (MDRD) [8] and chronic kidney disease epidemiology collaboration (CKD-EPI) [9]. These equations have been used worldwide in epidemiological studies on CKD. Excretion of protein in urine is also a recommended best predictor parameter for the assessment of renal function at the early stage [10].

The effect of obesity on renal function in obese adults has not been adequately described. In many epidemiologic studies, body mass index (BMI) is used as a good measurement of obesity $[11,12]$. According to Asian revised guidelines, Asian Indians are categorized on the basis of BMI in overweight if BMI between 23.0 to $24.9 \mathrm{~kg} / \mathrm{m2}$ ) [13] and obesity if BMI $\geq 25 \mathrm{~kg} / \mathrm{m} 2$ [14]. Therefore, the present study is designed to assess the renal function parameters in normal, overweight, and obese subjects as
Categorized on the basis of BMI to find out the association of renal parameters with obesity.

\section{Material and Methods}

Study setting: This study was carried out in the Department of Medical Biochemistry, Gandhi Medical College, and Hamidia Hospital, Bhopal, Madhya Pradesh, India.

Type of study: A prospective observational crosssectional study.

Duration of study: From 15th April 2019 to 15th June 2019.

Sample Size: A total of 100 apparently healthy volunteers who have visited the Hamidia Hospital as the attendant of patients and healthy hospital staff were included as study subjects during the study period.

Inclusion criteria: The age group of 25-50 years, normotensive and normoglycemic participants were recruited for this study.

Exclusion criteria: The participants who were having diagnosed diabetes mellitus (DM), hypertension (HTN), metabolic syndrome (MS), previous renal disease, any $\mathrm{H} / \mathrm{O}$ intake of steroids, active urinary tract infections, and pregnant women were excluded from the study.

Body mass index (BMI) criteria: BMI was calculated by measuring the height (meter) with the study subject standing against an upright surface and weight $(\mathrm{kg})$ by making the subject stand in the center of the weighing machine. All study subjects were divided into three groups on the basis of body mass index (BMI) according to Asian Guideline [14]; Normal $(\mathrm{n}=33 ; \mathrm{BMI} ; 18.5-22.9 \mathrm{~kg} / \mathrm{m} 2)$, Overweight ( $n=33 ;$ BMI; $23-24.9 \mathrm{~kg} / \mathrm{m} 2)$ and Obese $(n=34 ; B M I ; \geq 25 \mathrm{~kg} / \mathrm{m} 2)$ group.

Ethical consideration and permission: Ethical clearance was taken from the Institutional Ethics Committee (IEC), Gandhi Medical College, Bhopal (letter no.10028/MC/IEC/2018, dated 12/04/2019) prior to starting this study.

Sample collection: Five milliliters of fasting venous blood sample was taken for biochemical investigations. The urine sample was collected for protein test.

Lab investigations: All biochemical investigations were carried out by Fully Automated Clinical Chemistry Analyzer (BA 400, BIOSYSTEMS S.A., 
Barcelona, Spain). Serum urea was estimated by the DAM method [15] and serum creatinine was measured by Jaffe's kinetic method [16]. Normal serum creatinine level was considered up to 1.2 $\mathrm{mg} / \mathrm{dl}$. The estimated glomerular filtration rate (eGFR) was calculated by the Modification of Diet in Renal Disease (MDRD) equation [8]. A spot urinary protein (albumin) was measured using a visually read dipsticks (urine test strips, SD UroColorTM) method.

Renal impairment: eGFR less than $60 \mathrm{ml} / \mathrm{min} / 1.73$ $\mathrm{m} 2$ was considered an indicator of renal impairment/renal dysfunction.

Proteinuria: The proteinuria result was described as no proteinuria (no protein excretion) and trace urinary proteinuria $(1+, 2+$, and $3+)$.

Data analysis: Data was expressed as Mean \pm SD. Anthropometric and biochemical parameters between groups were compared by using unpaired Student's t-test. Correlation between various parameters was done by using Pearson's correlation coefficient. $p<0.05$ was considered as statistically significant level. All these statistical analyses were done by using SPSS version 20.0.

\section{Results}

The present study was conducted in 100 study subjects which included 48 males and 52 females. The study group was further divided on the basis of BMI into normal, overweight, and obese study groups as given in [Table 1] with the maximum number of subjects are falling into obese subgroups (34\%). Table 1 also shows more number of females as compared to males in both overweight (20 females and 13 males) and obese groups (18 females and 16 males).

Table-1: Distribution of study subjects according to gender and BMI.

\begin{tabular}{|c|c|c|c|c|c|c|}
\hline \multirow[t]{2}{*}{ BMI $(K g / m 2)$} & \multicolumn{2}{|c|}{ Male $(n=48)$} & \multicolumn{2}{|c|}{ Female $(n=52)$} & \multicolumn{2}{|c|}{ Total $(n=100)$} \\
\hline & $\mathrm{N}$ & $\%$ & $\mathrm{~N}$ & $\%$ & $\mathrm{~N}$ & $\%$ \\
\hline $\begin{array}{l}\text { Normal (18.5- } \\
22.9 \mathrm{Kg} / \mathrm{m} 2)\end{array}$ & 18 & $37.0 \%$ & 15 & $28.80 \%$ & 33 & $33 \%$ \\
\hline $\begin{array}{l}\text { Overweight (23- } \\
24.9 \mathrm{Kg} / \mathrm{m} 2 \text { ) }\end{array}$ & 13 & $27.0 \%$ & 20 & $38.46 \%$ & 33 & $33 \%$ \\
\hline $\begin{array}{l}\text { Obese }(\geq 25 \\
\mathrm{Kg} / \mathrm{m} 2)\end{array}$ & 17 & $35.4 \%$ & 17 & $32.69 \%$ & 34 & $34 \%$ \\
\hline
\end{tabular}

Table-2: Anthropometric and renal function parameters in normal, overweight, and obese study subjects.

\begin{tabular}{|c|c|c|c|c|c|c|}
\hline Parameters & Normal $(n=33)$ Mean \pm SD & Overweight $(\mathrm{n}=33$ ) Mean \pm SD & Obese $(n=34)$ Mean \pm SD & $\mid * \mathrm{p}$-value $\mid$ & \#p-value & $\$ p$-value \\
\hline Height (m) & $1.66 \pm 0.09$ & $1.64 \pm 0.05$ & $1.68 \pm 1.04$ & 0.343 & 0.912 & 0.826 \\
\hline Weight (kg) & $59.41 \pm 8.09$ & $63.77 \pm 7.81$ & $77.09 \pm 10.99$ & 0.029 & $<0.0001$ & $<0.0001$ \\
\hline BMI (Kg/m2) & $21.14 \pm 1.31$ & $23.86 \pm 1.27$ & $28.00 \pm 2.05$ & $\mid<0.0001$ & $<0.0001$ & $<0.0001$ \\
\hline Serum urea $(\mathrm{mg} / \mathrm{dl})$ & $35.1 \pm 4.42$ & $39.2 \pm 5.76$ & $48.03 \pm 4.74$ & 0.003 & $\mid<0.0001$ & $<0.0001$ \\
\hline Serum creatinine $(\mathrm{mg} / \mathrm{dl})$ & $0.82 \pm 0.10$ & $0.97 \pm 0.20$ & $1.10 \pm 0.21$ & 0.003 & $<0.0001$ & $<0.013$ \\
\hline eGFR $(\mathrm{ml} / \mathrm{min} / 1.73 \mathrm{~m} 2)$ & $98.1 \pm 10.72$ & $75.03 \pm 10.82$ & $68.3 \pm 10.14$ & $<0.0001$ & $\mid<0.0001$ & 0.010 \\
\hline
\end{tabular}

Data are presented as Mean $\pm \mathrm{SD}, \mathrm{BMI}=$ body mass index, eGFR = estimated glomerular filtration rate, $\mathrm{p}<0.05$; significant level, *comparison between normal and overweight subjects; \#comparison between normal and obese subjects and \$comparison between overweight and obese subjects.

Table-3: Correlation between urea, creatinine, and eGFR and BMI among subjects.

\begin{tabular}{|l|l|l|l|}
\cline { 1 - 1 } \multicolumn{1}{|c|}{$\mathrm{N}=100$} & \multicolumn{1}{|c|}{$\begin{array}{c}\text { Serum urea } \\
(\mathrm{mg} / \mathrm{dl})\end{array}$} & $\begin{array}{c}\text { Serum creatinine } \\
(\mathrm{mg} / \mathrm{dl})\end{array}$ & \multicolumn{1}{c|}{$\begin{array}{c}\text { eGFR } \\
(\mathrm{ml} / \mathrm{min} / 1.73 \mathrm{~m} 2)\end{array}$} \\
\cline { 1 - 3 } $\mathrm{R}$ & 0.266 & 0.239 & -0.281 \\
\hline $\mathrm{p}$-value & 0.007 & 0.01 & 0.004 \\
\hline
\end{tabular}

$P<0.05$; significant level, $r=$ correlation coefficient,
$N=$ number

Table 4: Distribution of among study subjects for renal dysfunction.

\begin{tabular}{|l|l|l|l|l|}
\hline \multicolumn{1}{|c|}{ Parameter (s) } & \multicolumn{3}{|c|}{ N (\%) } & \multicolumn{1}{|c|}{ N (\%) } \\
\cline { 2 - 5 } & $\begin{array}{l}\text { Normal }(\mathrm{n} \\
=33)\end{array}$ & $\begin{array}{l}\text { Overweight } \\
(\mathrm{n}=33)\end{array}$ & $\begin{array}{l}\text { Obese }(\mathrm{n} \\
=34)\end{array}$ & $\begin{array}{l}\text { Total subjects ( } \\
=100)\end{array}$ \\
\hline $\begin{array}{l}\text { High Blood urea ( }>45 \\
\mathrm{mg} / \mathrm{dl})\end{array}$ & $1(0.33 \%)$ & $1(0.33 \%)$ & $\begin{array}{l}2 \\
(0.68 \%)\end{array}$ & $4(4.00 \%)$ \\
\hline $\begin{array}{l}\text { High blood creatinine } \\
(>1.2 \mathrm{mg} / \mathrm{dl})\end{array}$ & $1(0.33 \%)$ & $1(0.33 \%)$ & $\begin{array}{l}3 \\
(1.02 \%)\end{array}$ & $5(5.00 \%)$ \\
\hline $\begin{array}{l}\text { Low eGFR }(<60 \\
\mathrm{ml} / \mathrm{min} / 1.73 \mathrm{~m} 2)\end{array}$ & $0(0.00 \%)$ & $1(0.33 \%)$ & $\begin{array}{l}2 \\
(0.68 \%)\end{array}$ & $3(3.00 \%)$ \\
\hline \begin{tabular}{l} 
Proteinuria $(>+1)$ \\
\hline
\end{tabular} & $0(0.00 \%)$ & $0(0.00 \%)$ & $\begin{array}{l}2 \\
(2.00 \%)\end{array}$ & $2(2.00 \%)$ \\
\hline
\end{tabular}


EGFR $=$ estimated glomerular filtration rate, $n=$ number, $\%=$ percentage

Table 2 shows the values of all the anthropometric parameters and the laboratory investigations carried out in normal, overweight, and obese study groups. There was a significant difference in the BMI of all the study groups. Serum urea and creatinine levels in obese individuals were significantly raised as compared to normal subjects although they were in the normal ranges. The eGFR (MDRD) was also significantly raised in both overweight as well as obese groups as compared to the normal study group.

There was a statistically significant correlation found between BMI and renal function parameters such as urea, creatinine, and estimated glomerular filtration rate as shown in Table 3.

In Table4, among study subjects, total $4.0 \%$ subjects had high blood urea and $5.0 \%$ had $>1.2$ $\mathrm{mg} / \mathrm{dl}$ creatinine. The prevalence of low eGFR was found $3.0 \%$ out of that $2.0 \%$ prevalence was found in the obese group. A total of $2.0 \%$ prevalence of proteinuria observed among subjects and especially in obese subjects.

\section{Discussion}

Chronic kidney disease is a common and increasing public health problem worldwide $[17,18]$. This is the first hospital-based study to estimate renal impairment in Central Indian adults with obesity. In the present study, the prevalence of obesity (BMI $\geq 25 \mathrm{~kg} / \mathrm{m2}$ ) among Central Indian adults was 34\%. In the North Indian population, Sigh NP et al have reported $26.8 \%$ of the prevalence of obesity [19] which was lower in comparison to the present study result.

Also, the prevalence of CKD in the present study subjects was found at $3.0 \%$. The current study is aware of some studies which reported the prevalence of CKD in India. These studies reported CKD prevalence of $0.79 \%$ [20] and $1.39 \%$ [21]. However, these studies had some limitations. The variation in the prevalence rate in different settings may be due to different criteria for the assessment of CKD, age, gender, and urban or rural settings.

In support of our result, Singh NP et al have reported $4.2 \%$ CKD prevalence by considering low eGFR criteria which were estimated by MDRD formula [19]. Creatinine is the anhydrous form of creatine that is present in muscles. Creatinine is
Filtered by the glomerulus and thus, serum creatinine estimation is considered as an indirect measure of glomerular filtration. Diminishing of GFR results in the rise of serum creatinine and urea levels [22].

In the present study, obese subjects were showed significantly higher levels of urea and creatinine as compared to normal healthy subjects group. Progressively rose in urea and creatinine with increasing BMI indicating increase renal perfusion and hyper-filtration in study subjects [23]. The interesting finding of the present study was that levels of creatinine increased proportionally to the levels of urea. In support of our findings, other studies were also reported a similar trend $[24,25]$.

Very less attention has been paid to the link between increased BMI and CKD, however, Hall JE et al have shown an association between CKD prevalence and BMI [23]. In the present study, a statistically significant negative correlation was found between eGFR and BMI. This result suggests that increasing BMI leads to renal dysfunction and those subjects who have high BMI had renal dysfunction.

Dada SA et al have reported a similar result in their study [26]. In contrast to our result, Hobbs et al have reported a lack of relationship between BMI and eGFR [27]. The present study has shown a $3.0 \%$ prevalence of low eGFR among adults. A study of Singh NP et al have reported $4.2 \%$ of low eGFR prevalence in the North Indian population with MDRD equation [19] however, it was slightly higher than the present study population.

The current study, reported excretion of protein in urine confirmed by dipsticks method. Proteinuria was found higher in the obese group compared to overweight and normal healthy subjects and progressively raised with increasing BMI. Our findings were consistent with the other studies that reported a link between higher BMI and albuminuria [28]. The prevalence of proteinuria was found at $3.0 \%$ in the present study. Some cross-sectional studies in different parts of India estimated prevalence rate between $0.47 \%$ to $4.41 \%$ $[19,20,29]$ and our result also in a similar trend.

\section{Limitations}

A major limitation of this study is the small sample size. Another limitation of this study is that the current study did not use isotope dilution mass spectrometry (IDMS) traceable creatinine method. 
Using a single measure of dipsticks for proteinuria in place of urinary albumin/creatinine ratio (ACR) is also an important limitation of the present study. $\mathrm{W} / \mathrm{H}$ ratio is also an alternative anthropometric index of obesity however, it was not calculated in this study.

\section{Conclusion}

Obesity is a major growing health concern in India due to its increasing prevalence found in the younger adult population. Our results confirmed that increasing BMI has a significant association with renal function parameters and should be considered to determine the early changes in renal function and renal glomerular injury with an increase in body weight. Keeping a healthy rage BMI may contribute to the prevention of renal impairment.

\section{What does this study add to the existing knowledge}

Early-stage detection of renal function tests in obese subjects reduces the risk of renal problems. Obesity is one of the important factors to increase renal impairment in normal healthy subjects.

\section{Author's contribution}

Dr. Pawan Kumar Kare had conceptualized the study, prepared the study protocol, conducted the data collection, statistical analysis, and manuscript writing. Dr. Amit Singh Ray, Dr. Haresingh Makwane, and Mr. Chitransh Garg had provided key inputs on methodology during protocol preparation, supported in data compilation and data analysis. Dr. Pawan Kumar Kare and Dr. Tripti Saxena have edited all the drafts, revised the manuscript, and approved the final draft of the manuscript.

\section{Acknowledgments}

The authors are thankful to the technical staff of the Department of Medical Biochemistry, GMC, Bhopal, and Hamidia Hospital for their support.

\section{Reference}

01. Ranjani H, Anjana RM, Garg R, Anand K. Epidemiology of childhood overweight and obesity in India- A systemic Review. Indian J Med Res. 2016;143(2)160-174.

doi: [Article] [Crossref]
02. WHO. Obesity and Overweight Fact Sheet 311. WHO. 2015.

Available at [Article] [Crossref]

03. Karla S, Unikrishnan A. Obesity in India- The weight of the Nation. J Med Nutraceut. 2012;1(1)37-41. doi: [Article] [Crossref]

04. Sam S, Mazzone T. Adipose tissue changes in obesity and the impact on metabolic function. Trans Res. 2014;164(4)284-292. doi: [Article] [Crossref]

05. Kiortsis DN, Christou MA. Management of obesity-induced kidney disease- A critical review of the literature. Obes facts. $2012 ; 5(6) 821-832$. doi: [Article] [Crossref]

06. Gelber RP, Kurth T, Kausz AT, Manson, JE, Buring JE, Levey AS, et al. Association between body mass index and CKD in apparently healthy men. Am J Kidney Dis. 2005;46(5)871-880.

doi: [Article] [Crossref]

07. Kramer H, Luke A, Bidani A, Cao G, Cooper R, McGee $D$. Obesity and prevalent and incident CKD the Hypertension Detection and Follow-Up Program. Am J Kidney Dis. 2005;46(4)587-594. doi: [Article] [Crossref]

08. Levey AS, Coresh J, Greene T, Stevens LA, Zhang YL. Using standardized serum creatinine values in the modification of diet in renal disease study equation for estimating glomerular filtration rate. Ann Intern Med. 2006;145(4)247-254.

doi: [Article] [Crossref]

09. Levey AS, Stevens LA, Schmid CH, Zhang $Y L$, Castro AF, Feldman $\mathrm{HI}$, et al. A new equation to estimate glomerular filtration rate. Ann Intern Med. 2009;150(9)604-612.

[Crossref]

10. Wickman C, Kramer H. Obesity and kidney disease, Potential mechanisms. Semin Nephrol. 2013;33(1)14-22. doi: [Article] [Crossref]

11. Khashayar $P$, Aghaei Meybodi H, Rezaei Hemami M, Larijani B. Role of obesity variables in detecting hypertension in an Iranian population. High Blood Press Cardiovasc Prev. 2017;24(3)305-312. doi: [Article] [Crossref] 
12. Cho YG, Song HJ, Kim JM, Park KH, Paek YJ, Cho Jj, et al. The estimation of cardiovascular risk factors by body mass index and body fat percentage in Korean male adults. Metabol. 2009;58(6)765-771.

doi: [Article] [Crossref]

13. Raatikainen K, Heiskanen N, Heinonen S. Transition from overweight to obesity worsens pregnancy outcome in a BMI-dependent manner. Obesity (Silver Spring). $2006 ; 14(1) 165-171$.

doi: [Article] [Crossref]

14. Mishra A, Chowbey P, Makkar BM, Vikram NK, Wasir JS, Chadha D, et al. Consensus statement for diagnosis of obesity, abdominal obesity and the metabolic syndrome for Asian Indians and recommendations for physical activity, medical and surgical management. J Assoc Physicians India. 2009;57;163-170.

[Crossref]

15. Rosenthal, HL. Determination of urea in blood and urine with diacetyl monoxime. Anal Chem. 1955;27(12)1980-1982.

doi: [Article] [Crossref]

16. Bowers LD, Wong ET. Kinetic serum creatinine assays- II, A critical evaluation and review. Clin Chem. 1980;26(5)555-561.

[Crossref]

17. Agaba EI, Mamven MH, Agaba PA, Tzamaloukas $A H$. Self-reported screening of nephrologists for chronic kidney disease- a nationwide survey. Int Urol Nephrol. 2009;41(4)973-976.

doi: [Article] [Crossref]

18. Alebiosu CO, Ayodele OE. The global burden of chronic kidney disease and the way forward. Ethn Dis. 2005;15(3)418-423.

[Crossref]

19. Singh NP, Ingle GK, Saini VK, Jami A, Beniwal $P$, Lal $M$, et al. Prevalence of low glomerular filtration rate, proteinuria and associated risk factors in North India using Cockcroft-Gault and Modification of Diet in Renal Disease Equationan observational, cross-sectional study. BMC Nephrol. 2009;10(4)1-13.

doi: [Article] [Crossref]

20. Agarwal SK, Dash SC, Irshad M, Raju S, Singh $R$, Pandey RM. Prevalence of chronic renal failure in adults in Delhi, India. Nephrol Dial Transplant. 2005;20(8)1638-1642.

doi: [Article] [Crossref]
21. Mani MK. Experience with a program for prevention of chronic renal failure in India. Kidney Int Suppl. 2005;95;S75-S78.

[Crossref]

22. Sabiullah M. Estimation of serum creatinine, blood urea nitrogen and urine analysis in patients with diabetes to assess the renal impairments. Int J Adv Biochem Res. 2017;3(2)1-4. doi: [Article] [Crossref]

23. Hall JE, Henegar JR, Dwyer TM, Liu J, Da Silva $A A$, Kuo JJ, et al. Is obesity a major cause of chronic kidney disease?. Adv Ren Replce Ther. 2004;11(1)41-54. doi: [Article] [Crossref]

24. Mittal A, Sathian B, Kumar A, Chandrashekharan $N$, Sunka A. Diabetes mellitus as a potential risk factor for renal disease among Nepalese- A hospital based control study. Nepal J Epidemiol. 2010;1(1)22-25. doi: [Article] [Crossref]

25. Kapoor S, Cohen D, Townsend R. Effects of Chronic Kidney Disease on Pulse Counter Analysis. Indian J Nephrol. 2007;17(3)91-94. [Crossref]

26. Dada SA, Raimi TH, Aremu AO. Association between Body Mass Index as a measure of excess weight and glomerular filtration rate among Healthy Nigerian Population. J Nephrol Res. 2018;4(1)153-158.

doi: $\quad 10.17554 / j$. issn.2410-0579.2018.04.32 [Crossref]

27. Hobbs H, Farmer C, Irving J, Klebe B, Stevens P. Is high body mass index independently associated with diminished glomerular filtration rate?- An epidemiological study. J Ren Care. 2011;37(3)148-154. doi: [Article] [Crossref]

28. Fox CS, Larson MG, Leip EP, Gulleton B, Wilson PW, Levy D. Predictors of new-onset kidney disease in a community-based population. JAMA. 2004;291(7)844-850. doi: [Article] [Crossref]

29. Ahmed I, John GT, Kirubakaran MG, Jacob CK, Muliyil J. Prevalence of proteinuria in rural adults population in Tamil Nadu. Indian $\mathrm{J}$ Med Res. 2006;124(2)185-188.

[Crossref] 